\title{
Epidural anesthesia and postoperative analgesia with ropivacaine and fentanyl in off-pump coronary artery bypass grafting: a randomized, controlled study
}

\author{
Mikhail Y Kirov ${ }^{1,2,3,4^{*}}$, Alexey V Eremeev ${ }^{2}$, Alexey A Smetkin ${ }^{1,2}$ and Lars J Bjertnaes E $^{3,4}$
}

\begin{abstract}
Background: Our aim was to assess the efficacy of thoracic epidural anesthesia (EA) followed by postoperative epidural infusion (EI) and patient-controlled epidural analgesia (PCEA) with ropivacaine/fentanyl in off-pump coronary artery bypass grafting (OPCAB).

Methods: In a prospective study, 93 patients were scheduled for OPCAB under propofol/fentanyl anesthesia and randomized to three postoperative analgesia regimens aiming at a visual analog scale (VAS) score $<30 \mathrm{~mm}$ at rest. The control group ( $n=31$ ) received intravenous fentanyl $10 \mu \mathrm{g} / \mathrm{ml}$ postoperatively $3-8 \mathrm{~mL} / \mathrm{h}$. After placement of an epidural catheter at the level of $\mathrm{Th}_{2}-\mathrm{Th}_{4}$ before OPCAB, a thoracic El group $(n=31)$ received EA intraoperatively with ropivacaine $0.75 \% 1 \mathrm{mg} / \mathrm{kg}$ and fentanyl $1 \mu \mathrm{g} / \mathrm{kg}$ followed by continuous El of ropivacaine $0.2 \% 3-8 \mathrm{~mL} / \mathrm{h}$ and fentanyl $2 \mu \mathrm{g} / \mathrm{mL}$ postoperatively. The PCEA group $(n=31)$, in addition to EA and El, received PCEA (ropivacaine/ fentanyl bolus $1 \mathrm{~mL}$, lock-out interval $12 \mathrm{~min}$ ) postoperatively. Hemodynamics and blood gases were measured throughout $24 \mathrm{~h}$ after OPCAB.
\end{abstract}

Results: During $O P C A B$, EA decreased arterial pressure transiently, counteracted changes in global ejection fraction and accumulation of extravascular lung water, and reduced the consumption of propofol by 15\%, fentanyl by $50 \%$ and nitroglycerin by a 7-fold, but increased the requirements in colloids and vasopressors by 2- and 3-fold, respectively $(P<0.05)$. After OPCAB, PCEA increased $\mathrm{PaO}_{2} / \mathrm{FiO}_{2}$ at $18 \mathrm{~h}$ and decreased the duration of mechanical ventilation by $32 \%$ compared with the control group $(P<0.05)$.

Conclusions: In OPCAB, EA with ropivacaine/fentanyl decreases arterial pressure transiently, optimizes myocardial performance and influences the perioperative fluid and vasoactive therapy. Postoperative El combined with PCEA improves lung function and reduces time to extubation.

Trial Registration: NCT01384175

Keywords: epidural anesthesia, analgesia, patient-controlled analgesia, off-pump coronary artery bypass grafting

\section{Background}

Coronary artery bypass grafting (CABG) is one of the most common cardiosurgical interventions. In many institutions, CABG is performed without cardiopulmonary bypass $(\mathrm{CPB})$, a modification which is commonly

\footnotetext{
* Correspondence: mikhail_kirov@hotmail.com

'Department of Anesthesiology and Intensive Care Medicine, Northern State Medical University, Troitsky avenue 51, Arkhangelsk, 163000, Russian

Federation

Full list of author information is available at the end of the article
}

referred to as off-pump coronary artery bypass grafting (OPCAB) [1-4]. The off-pump technique enables coronary revascularization on the beating heart, thereby reducing the risk of complications associated with $\mathrm{CPB}$. However, OPCAB can be accompanied by hemodynamic alterations, postoperative pain, and respiratory dysfunction, requiring thorough monitoring and perioperative care [3-6].

In cardiosurgical patients, high thoracic epidural anesthesia (EA) with local anesthetics and opioids can

\section{Biomed Central}

(c) 2011 Kirov et al; licensee BioMed Central Ltd. This is an Open Access article distributed under the terms of the Creative Commons Attribution License (http://creativecommons.org/licenses/by/2.0), which permits unrestricted use, distribution, and reproduction in any medium, provided the original work is properly cited. 
provide effective analgesia and reduce the number of perioperative complications [6-8]. However, the use of EA in coronary surgery is controversial, and it is still unclear whether EA influences lung fluid balance, cardiopulmonary function and clinical outcome in OPCAB. Thus, the method requires further evaluation and its potential benefits in coronary patients should be weighed against its risks $[8,9]$.

Patient-controlled epidural analgesia (PCEA) is an attractive technique for postoperative pain relief. However, in OPCAB the role of PCEA with administration of a ropivacaine/fentanyl mixture via a thoracic epidural catheter remains unsettled.

We hypothesized that after OPCAB, thoracic epidural analgesia with ropivacaine and fentanyl aiming at a visual analog scale (VAS) score $<30 \mathrm{~mm}$ will be associated with improved cardiopulmonary parameters in comparison with intravenously administered analgesia. If the hypothesis is confirmed, we expect that epidural administration of ropivacaine and fentanyl, including a patient-controlled mode, might reduce the duration of mechanical ventilation. Thus, the duration of mechanical ventilation and the changes in cardiopulmonary variables served as the primary and the secondary study end-points, respectively. Using these end-points, the aim of our study was to assess the influence of EA followed by postoperative PCEA with ropivacaine/fentanyl on cardiopulmonary function in the perioperative management of OPCAB patients.

\section{Methods \\ Patients}

The study protocol and informed consent form were approved by the Ethics Committee of Northern State Medical University, Arkhangelsk, Russian Federation. Written informed consent was obtained from every patient.

The study was performed in a 900-bed university hospital. During the period from January of 2008 to September of 2009, 93 adult patients with coronary artery disease, ranked ASA III and scheduled for elective OPCAB, were enrolled into a prospective randomized study. Exclusion criteria were age $<18$ years, severe valve dysfunction or peripheral vascular disease, simultaneous interventions (carotid endarterectomy, aneurysm repair, etc.), or transfer to $\mathrm{CPB}$ during surgery.

\section{Anesthesia and surgery}

All patients received standard premedication with diazepam (Seduxen; Gedeon Richter, Budapest, Hungary). After establishment of routine hemodynamic monitoring with ECG including ST segment analysis, blood pressure, and $\mathrm{SpO}_{2}$ measurements, anesthesia was induced with intravenous midazolam (Dormicum, F. Hoffmann-
La Roche Ltd., Switzerland) $0.07 \mathrm{mg} / \mathrm{kg}$, propofol (Diprivan, AstraZeneca, UK) $1 \mathrm{mg} / \mathrm{kg}$, and fentanyl (Fentanyl, Moscow Endocrine Factory, Russian Federation) 3-5 $\mu \mathrm{g}$ / kg. Neuromuscular blockade was induced with intravenous pipecuronium (Arduan, Gedeon Richter, Hungary) $0.1 \mathrm{mg} / \mathrm{kg}$ and maintained with repeated doses of pipecuronium $0.015 \mathrm{mg} / \mathrm{kg} / \mathrm{h}$. Anesthesia was maintained with propofol $3 \mathrm{mg} / \mathrm{kg} / \mathrm{h}$ from the onset and continuing with $3-5 \mathrm{mg} / \mathrm{kg} / \mathrm{h}$, and fentanyl $2-4 \mu \mathrm{g} / \mathrm{kg} / \mathrm{h}$, aiming at heart rate within $50-90$ beats/min and mean arterial pressure within $60-80 \mathrm{~mm} \mathrm{Hg}$.

Mechanical ventilation in the operating room was performed by using a semi-closed anesthetic circuit (Fabius, Dräger, Germany) with $\mathrm{FiO}_{2}$ 0.5, tidal volume 7-8 mL/ $\mathrm{kg}$, respiratory rate $12-14 / \mathrm{min}$ aiming at a $\mathrm{PaCO}_{2}$ of $35-$ $45 \mathrm{~mm} \mathrm{Hg}$, positive end-expiratory pressure $4 \mathrm{~cm} \mathrm{H}_{2} \mathrm{O}$, and fresh gas flow of $1 \mathrm{~L} / \mathrm{min}$.

Fluid therapy included infusion of Ringer's lactate at rates of $6-7 \mathrm{~mL} / \mathrm{kg} / \mathrm{h}$ prior to and during anesthesia and 2-3 $\mathrm{mL} / \mathrm{kg} / \mathrm{h}$ during the first $6 \mathrm{~h}$ postoperatively. In cases of hypovolemia, diagnosed by volumetric hemodynamic monitoring (Figure 1), we administered Gelofusin (Braun, Germany) $6-8 \mathrm{~mL} / \mathrm{kg}$ over $30 \mathrm{~min}$. A transfusion trigger was hemoglobin level $<8 \mathrm{~g} / \mathrm{dL}$.

All patients were operated by the same team of surgeons using midline sternotomy, and Acrobat SUV OM9000S (Guidant, Santa Clara, USA) device for stabilization of the heart during revascularization. After pericardiotomy, we administered heparin 100 Units/kg aiming at maintenance of activated clotting time $>250 \mathrm{sec}$ during revascularization.

\section{Randomization and protocol}

The patients were randomized to three groups using the envelope method. All groups received lornoxicam (Xefocam, Nycomed, Austria) $8 \mathrm{mg}$ IV before OPCAB and every $12 \mathrm{~h}$ during two postoperative days.

Figure 2 displays a flowchart of the study groups. The control group $(n=31)$ had no epidural catheter and received fentanyl $10 \mu \mathrm{g} / \mathrm{ml}$ intravenously at a rate of 3-8 $\mathrm{mL} / \mathrm{h}$ postoperatively.

In two other groups, an epidural catheter (Perifix 16G, Braun, Germany) was inserted at $\mathrm{Th}_{2}-\mathrm{Th}_{4}$ level before induction of anesthesia. The epidural space was identified by the loss-of-resistance technique; 3 to $4 \mathrm{~cm}$ of the catheter was inserted into the epidural space followed by administration of a test dose of $1 \mathrm{~mL}$ of $2 \%$ lidocaine.

After placement of the epidural catheter and induction of anesthesia, the thoracic epidural infusion (EI) group $(\mathrm{n}=31)$ received EA with ropivacaine (Naropin, AstraZeneca, UK) $0.75 \% 1 \mathrm{mg} / \mathrm{kg}$ and fentanyl $1 \mu \mathrm{g} / \mathrm{kg}$ followed by postoperative continuous EI of ropivacaine $0.2 \%$ and fentanyl $2 \mu \mathrm{g} / \mathrm{mL}$ at a rate of $3-8 \mathrm{~mL} / \mathrm{h}$. 


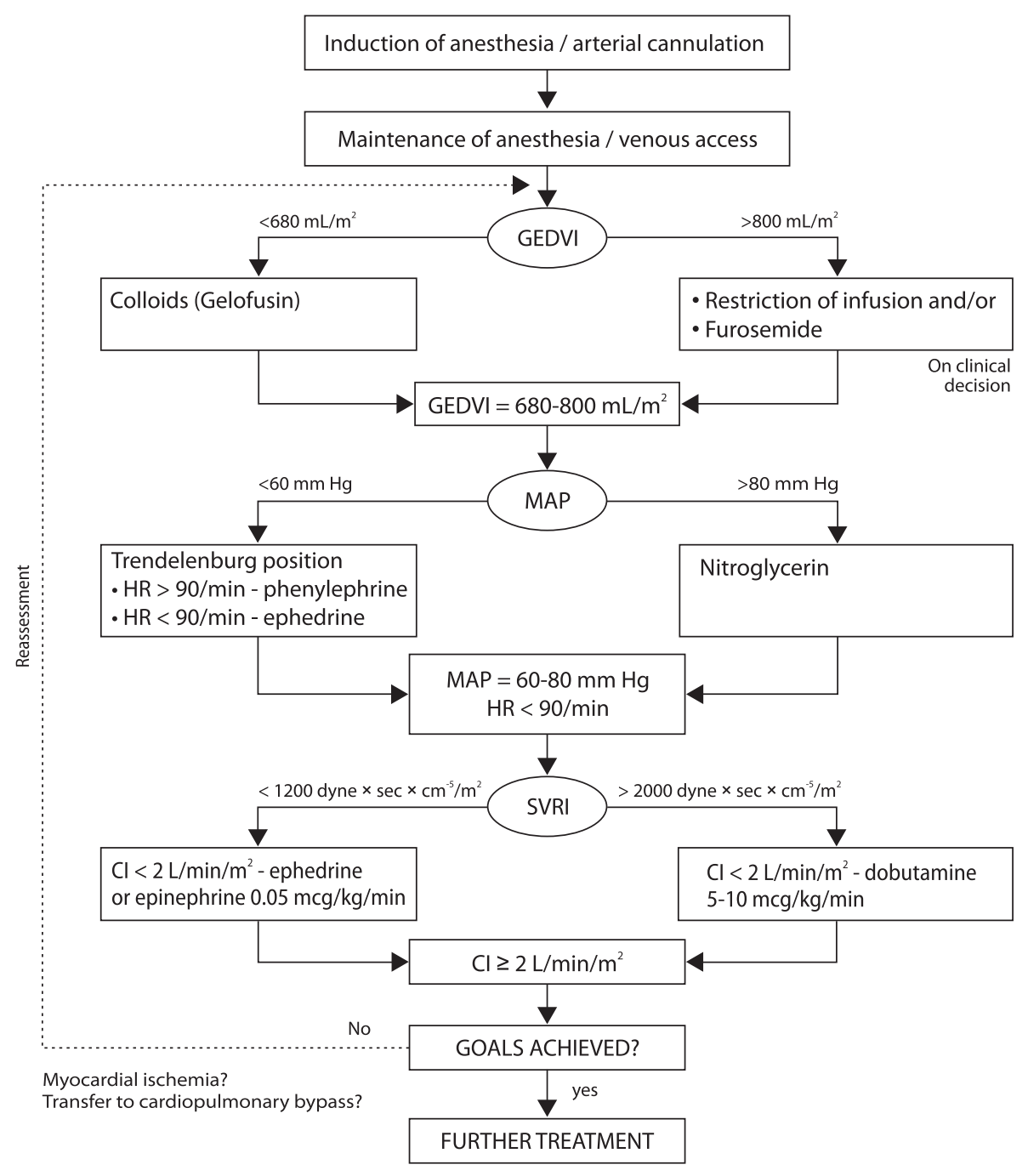

Figure 1 Flowchart showing algorithm for hemodynamic monitoring and perioperative management. MAP: mean arterial pressure; HR: heart rate; GEDVI: global end-diastolic volume index; Cl: cardiac index; SVRI: systemic vascular resistance index. During anesthesia, this algorithm was used to correct HR and MAP only if the doses of propofol $3-5 \mathrm{mg} / \mathrm{kg} / \mathrm{h}$ and fentanyl $2-4 \mathrm{\mu g} / \mathrm{kg} / \mathrm{h}$ were unable to maintain HR within $50-90$ beats/min and MAP within $60-80 \mathrm{~mm} \mathrm{Hg}$. For perioperative management, we used the following doses of intravenous agents: ephedrine 5-10 $\mathrm{mg}$, phenylephrine 0, 05-1 mg, nitroglycerine $0,3-3 \mathrm{mg} / \mathrm{h}$ and furosemide $10-20 \mathrm{mg}$.

The PCEA group $(\mathrm{n}=31)$ received the same intraoperative therapy as the EI group but, at variance, this was combined with postoperative PCEA using a programmable infusion pump (Graseby 3300 , UK) with ropivacaine/fentanyl bolus $1 \mathrm{~mL}$, which could be administered on the patients discretion with a lock-out interval of $12 \mathrm{~min}$. The patients started to use PCEA after recovery from anesthesia.

The postoperative analgesia was administered by the attending physician, who adjusted the infusion rate of fentanyl in the control group and ropivacaine/fentanyl in the EI groups beginning from $3 \mathrm{~mL} / \mathrm{h}$ and aiming at a VAS score of $<30 \mathrm{~mm}$ at rest. All patients received aspirin postoperatively at a daily dose of $75 \mathrm{mg}$ per os.

\section{Measurements}

The femoral artery was catheterized with a $5 \mathrm{~F}$ arterial thermodilution catheter (Pulsiocath PV2015L20, Pulsion, Germany), which was connected to a LifeScope (Nihon Kohden, Japan) and a PiCCOplus (Pulsion Medical Systems, Germany) monitor for thermodilution measurements and continuous hemodynamic monitoring. After induction of anesthesia, an $8.5 \mathrm{~F}$ central venous catheter was inserted into the internal jugular vein. The 


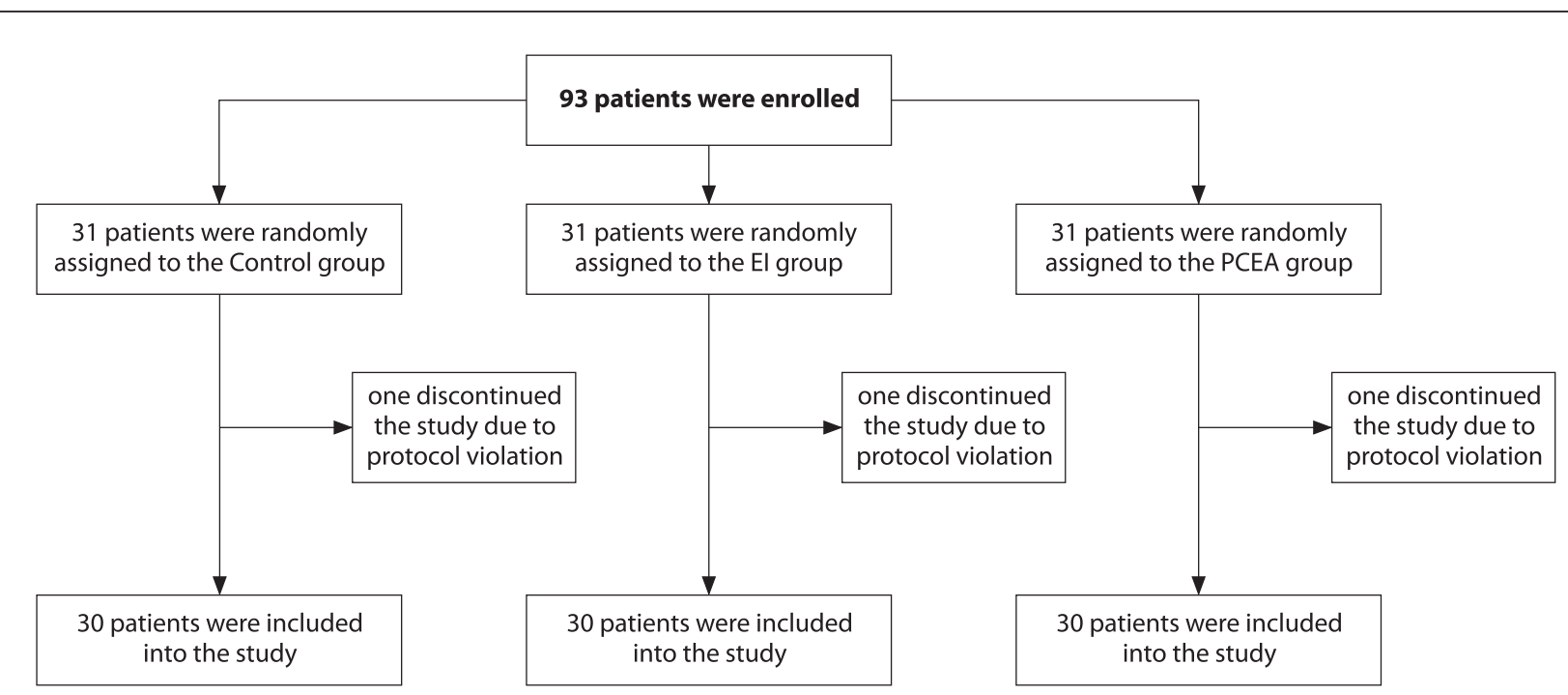

Figure 2 Flowchart of the study groups. El: epidural infusion group; PCEA: patient-controlled epidural analgesia group.

registered hemodynamic parameters included heart rate (HR), mean arterial pressure (MAP), and central venous pressure (CVP), as well as global end-diastolic volume index (GEDVI), cardiac index (CI), extravascular lung water index (EVLWI), cardiac function index (CFI), global ejection fraction (GEF), left ventricle contractility index (dPmax), and systemic vascular resistance index (SVRI).

The hemodynamic parameters were registered after induction of anesthesia, at the restraint of the heart by using the stabilizing devices, at $5 \mathrm{~min}$ after restoration of blood flow via the coronary grafts, at the end of surgery, and at $2,6,12,18$, and $24 \mathrm{~h}$ postoperatively. These time-points were selected for goal-directed hemodynamic adjustments (Figure 1).

Blood gases and plasma lactate concentration were measured after induction of anesthesia, at the end of surgery, and at $2,6,12,18$, and 24 h postoperatively using ABL800Flex (Radiometer, Denmark). Plasma concentrations of cortisol and troponin- $\mathrm{T}$ were measured before surgery and at 6 and $18 \mathrm{~h}$ postoperatively (Roche Diagnostics GmbH, Germany).

The severity of postoperative pain at rest and during coughing was assessed by the attending physician with VAS score at $6,12,18$, and $24 \mathrm{~h}$ after OPCAB. The level of sedation was also evaluated by the attending physician by means of the Ramsay's score. In addition, we recorded the drug consumption, the perioperative fluid balance and administration of fluids, inotropes and vasoactive drugs, perioperative adverse effects, duration of surgery and postoperative mechanical ventilation, lengths of postoperative ICU and hospital stay, and the mortality rate at Day 28.
Extubation criteria were the following: a cooperative, alert patient; adequate muscular tone; $\mathrm{SpO}_{2}>95 \%$ with $\mathrm{FiO}_{2}$ 0.5; $\mathrm{PaCO}_{2}<45 \mathrm{~mm} \mathrm{Hg}$; stable hemodynamics without inotrope/vasopressor support; absence of arrhythmias; and body temperature $>35^{\circ} \mathrm{C}$. Temporary pacing was not regarded as a contraindication to extubation.

The patients were discharged from hospital if they satisfied the following criteria: hemodynamic stability, independence in ambulation and feeding, afebrile with clean wound and no obvious infections, normal voiding and bowel movements, pain control on oral medications, and exercise tolerance. The doctor responsible for discharge from the hospital was unaware of the study groups.

\section{Statistical analysis}

For data collection and analysis, we used SPSS software (version 14.0; SPSS Inc., Chicago, IL, USA). Calculation of sample size was based on initial observations (10 cases in each group) and the hypothesis that postoperative PCEA will shorten the time to tracheal extubation by 90 min compared with the control group. In order to find a statistically significant difference with $\alpha$ of 0.05 and power of 0.8 , a sample size of 30 patients in each group proved to be sufficient. The normality of the data distribution was assessed using the Shapiro-Wilk test. In case of normal distribution, we used ANOVA and post hoc Dunnet test for comparison among the groups and repeated measures ANOVA followed by test of contrasts for intragroup comparisons. Non-parametrically distributed data were assessed by Friedman test followed by Wilcoxon test, respectively. The quantitative values are 
expressed as mean $\pm \mathrm{SD}$ and median $\left(25^{\text {th }}-75^{\text {th }}\right.$ percentiles) in accordance with data distribution. The discrete data were analyzed by two-sided chi-square test and expressed as patient number or percentage. For all tests, a $P$-value $<0.05$ was considered as significant.

\section{Results}

As shown in Table 1, we found no significant differences among the groups concerning demographic data, including co-morbidities and preoperative ejection fraction. Three patients (one patient in each group) who became hemodynamically unstable during CABG were transferred to $\mathrm{CPB}$ and excluded from further analysis (Figure 2). One of these patients (belonging to the EI group) required re-operation and died because of postoperative bleeding from the aorta. All the other patients survived to Day 28 and were discharged from hospital. Duration of surgery, as well as of ICU and hospital stays, did not differ among the groups. The duration of mechanical ventilation was reduced by $32 \%$ in the PCEA group $(P=0.04)$ and tended to decrease in the EI group $(P=0.14)$ compared with the control group (Table 1).

Table 2 displays changes in hemodynamics. In the groups receiving EA, MAP decreased transiently by $10-$ $15 \%$ during OPCAB $(P<0.05)$, but rose postoperatively without intergroup differences. After induction of anesthesia, all groups demonstrated reduced HR, CI, CFI, dPmax and GEF, and increased SVRI as compared to normal values. Perioperatively, $\mathrm{HR}, \mathrm{CI}$, and CFI rose in all groups whereas SVRI declined $(P<0.05)$. Compared to baseline, CVP increased significantly at the restraint of the heart and then decreased after $\mathrm{OPCAB}$ in all groups $(P<0.05)$. Global end-diastolic volume index did not change significantly. In the EI and the PCEA groups, dPmax increased postoperatively by 70 $85 \%(P<0.05)$. By contrast, in the control group GEF decreased by $10-15 \%$ during OPCAB, and EVLWI rose by $22 \%$ during the restraint of the heart $(P<0.05)$.
Table 3 demonstrates blood gases and biochemical variables. In all groups, $\mathrm{pH}$ declined intraoperatively and during $6 \mathrm{~h}$ postoperatively, but increased significantly at $24 \mathrm{~h}$ in the groups receiving epidural analgesia. In parallel, $\mathrm{PaCO}_{2}$ decreased from intragroup baseline during 12-24 $\mathrm{h}$ in the EI group and during 18-24 $\mathrm{h}$ in the PCEA group but without differences with control group where $\mathrm{PaCO}_{2}$ also reduced at $24 \mathrm{~h}$. At $18 \mathrm{~h}, \mathrm{PaO}_{2} / \mathrm{FiO}_{2}$ was higher in the PCEA group $(P=0.03$ compared with controls). Plasma concentrations of lactate and glucose rose postoperatively in all groups; however, in the PCEA group lactate fell by $33 \%$ compared with the control group $(P=0.04)$ at $18 \mathrm{~h}$. After OPCAB, plasma concentrations of cortisol and troponin $\mathrm{T}$ increased without intergroup differences.

The VAS scores were within $20 \mathrm{~mm}$ at rest and 30 $\mathrm{mm}$ during coughing in all groups without intergroup differences excluding $12 \mathrm{~h}$ when VAS score was significantly lower in the PCEA group as compared to controls (Table 4). The level of postoperative sedation did not differ among the groups.

Table 5 shows that during OPCAB, EA reduced the consumption of propofol by $15 \%$ and fentanyl by $50 \%$ ( $P$ $<0.05$ ). The postoperative requirement of ropivacaine increased by $20 \%$ in the PCEA group as compared with the EI group $(P=0.03)$. In both EA groups, the requirement of nitroglycerin decreased by a 7 -fold intraoperatively and by a 2.5 -fold after OPCAB $(P<0.05)$. Intraoperative inotropes/vasopressors were administered more frequently in the EA groups as compared with the control group ( $43 \%$ vs. $13 \%$, respectively; $P=0.02)$. Colloids also were given more frequently in the patients receiving EA ( $75 \%$ vs. $37 \%, P=0.01)$. After OPCAB, the incidence of colloid administration was higher in the EI group compared with the other groups $(P<0.05)$. Intraoperative fluid balance increased by $21 \%$ in the EA groups $(P<0.05)$. There were no significant differences in blood loss, urine output, administration of crystalloids

Table 1 Main characteristics of patients undergoing OPCAB

\begin{tabular}{|c|c|c|c|}
\hline \multirow[t]{2}{*}{ Characteristic } & \multicolumn{3}{|c|}{ Groups } \\
\hline & $\begin{array}{l}\text { Control } \\
(n=30)\end{array}$ & $\begin{array}{c}\text { El } \\
(n=30)\end{array}$ & $\begin{array}{c}\text { PCEA } \\
(n=30)\end{array}$ \\
\hline Age, yrs & $58.6 \pm 9.1$ & $54.5 \pm 8.2$ & $53.6 \pm 7.0$ \\
\hline Gender, males/females, \% & $73 / 27$ & $90 / 10$ & $90 / 10$ \\
\hline Preoperative ejection fraction & $0.58 \pm 0.10$ & $0.58 \pm 0.08$ & $0.59 \pm 0.09$ \\
\hline Duration of surgery, min & $174 \pm 38$ & $149 \pm 36$ & $155 \pm 40$ \\
\hline Duration of mechanical ventilation, min & $358(266-455)$ & $300(180-385)$ & $245(199-345)^{*}$ \\
\hline Postoperative ICU stay, h & $59 \pm 29$ & $62 \pm 28$ & $59 \pm 25$ \\
\hline Duration of postoperative hospital stay, days & $16.0(14.8-20.3)$ & $15.0(14.0-18.5)$ & $15.0(14.0-18.3)$ \\
\hline
\end{tabular}

Data are presented as mean \pm SD or median $\left(25^{\text {th }}-75^{\text {th }}\right.$ percentiles).

* $P<0.05$ compared with the control group.

Control, control group; El, epidural infusion group; PCEA, patient controlled epidural analgesia group. 
Table 2 Hemodynamic parameters in patients undergoing OPCAB

\begin{tabular}{|c|c|c|c|c|c|c|c|c|c|c|}
\hline \multirow[t]{2}{*}{ Characteristic } & \multirow[t]{2}{*}{ Group } & \multicolumn{4}{|c|}{ Intraoperative period } & \multicolumn{5}{|c|}{ Postoperative period } \\
\hline & & $\begin{array}{l}\text { After induction } \\
\text { of anesthesia }\end{array}$ & $\begin{array}{l}\text { Fixation of } \\
\text { the heart }\end{array}$ & $\begin{array}{l}5 \text { min } \\
\text { after } \\
\text { start } \\
\text { flow }\end{array}$ & $\begin{array}{l}\text { End of } \\
\text { operation }\end{array}$ & 2 hours & 6 hours & 12 hours & 18 hours & 24 hours \\
\hline & Control & $79.9 \pm 13.5$ & $76.9 \pm 15.6$ & $74.6 \pm 14.3$ & $80.2 \pm 10.4$ & $89.9 \pm 15.3^{+}$ & $87.6 \pm 12.7^{+}$ & $82.5 \pm 14.8^{\#}$ & $80.1 \pm 13.1$ & $80.1 \pm 13.1$ \\
\hline \multirow[t]{3}{*}{ MAP, $\mathrm{mm} \mathrm{Hg}$} & El & $72.8 \pm 8.37$ & $67.8 \pm 13.5^{+}$ & $72.6 \pm 11.8$ & $74.2 \pm 12.6$ & $86.1 \pm 17.6^{+}$ & $81.2 \pm 14.9^{+}$ & $72.0 \pm 12.4$ & $76.1 \pm 12.4$ & $75.6 \pm 11.4$ \\
\hline & PCEA & $79.4 \pm 13.6$ & $67.5 \pm 12.1^{+}$ & $74.7 \pm 12.7$ & $72.6 \pm 11.4^{+}$ & $89.6 \pm 14.9^{+}$ & $89.4 \pm 17.5^{+}$ & $83.7 \pm 17.3^{\#}$ & $79.1 \pm 17.9$ & $82.3 \pm 17.0$ \\
\hline & Control & $50.0(42.3-59.8)$ & $59.5(51.3-64.8)^{+}$ & $62.5(50.5-70.5)^{\#+}$ & $61.0(55.3-74.5)^{\#+}$ & $77.5(71.0-85.0)^{+}$ & $87.5(77.5-98.0)^{+}$ & $87.0(80.3-101.0)^{\#+}$ & $82.5(75.0-96.8)^{+}$ & $83.5(77.0-94.5)^{+}$ \\
\hline \multirow[t]{3}{*}{$\mathrm{HR}, 1 / \mathrm{min}$} & El & $52.0(43.3-59.8)$ & $51.5(44.3-63.8)$ & $54.5(48.3-62.8)$ & $56.0(48.3-66.0)$ & $66.5(56.8-84.0)^{+}$ & $85.0(75.5-88.8)^{+}$ & $79.5(75.3-92.0)^{+}$ & $81.0(73.0-89.8)^{+}$ & $80.0(74.8-88.8)^{+}$ \\
\hline & PCEA & $54.0(48.5-64.0)$ & $55.0(49.0-63.0)$ & $58.0(54.0-65.0)$ & $61.0(55.0-66.5)$ & $71.0(64.0-86.5)^{+}$ & $91.0(82.0-105.0)^{+}$ & $89.0(83.0-94.0)^{\#+}$ & $86.0(78.5-91.5)^{+}$ & $86.0(80.5-93.5)^{+}$ \\
\hline & Control & $2.20 \pm 0.42$ & $2.43 \pm 0.59$ & $2.96 \pm 1.23^{+}$ & $2.70 \pm 0.80$ & $3.27 \pm 0.74^{+}$ & $3.55 \pm 0.83^{+}$ & $3.69 \pm 0.78^{+}$ & $3.39 \pm 0.38$ & $3.46 \pm 0.42^{+}$ \\
\hline \multirow[t]{3}{*}{$\mathrm{Cl}, \mathrm{l} / \mathrm{min} / \mathrm{m}^{2}$} & El & $2.20 \pm 0.44$ & $1.97 \pm 0.51$ & $2.55 \pm 0.33^{+}$ & $2.57 \pm 0.55^{+}$ & $3.12 \pm 0.69^{+}$ & $3.43 \pm 0.59^{+}$ & $3.43 \pm 0.53^{+}$ & $3.34 \pm 0.50$ & $3.32 \pm 0.44^{+}$ \\
\hline & PCEA & $2.15 \pm 0.46$ & $1.89 \pm 0.51$ & $2.81 \pm 0.75^{+}$ & $2.58 \pm 0.80$ & $3.27 \pm 0.87^{+}$ & $3.79 \pm 0.63^{+}$ & $3.46 \pm 0.49^{+}$ & $3.08 \pm 0.44$ & $3.40 \pm 0.46^{+}$ \\
\hline & Control & $3.47 \pm 1.18$ & $3.14 \pm 1.04$ & $3.88 \pm 1.42$ & $3.79 \pm 1.24$ & $4.71 \pm 1.83^{+}$ & $5.01 \pm 1.73^{+}$ & $5.56 \pm 1.92^{+}$ & $4.96 \pm 1.19^{+}$ & $4.98 \pm 1.11^{+}$ \\
\hline \multirow[t]{3}{*}{$\mathrm{CFI}, 1 / \mathrm{min}$} & El & $3.42 \pm 0.77$ & $3.03 \pm 0.65^{+}$ & $3.69 \pm 0.69$ & $3.65 \pm 0.87$ & $4.68 \pm 0.92^{+}$ & $5.25 \pm 0.76^{+}$ & $5.23 \pm 1.22^{+}$ & $5.13 \pm 1.14^{+}$ & $4.95 \pm 1.29^{+}$ \\
\hline & PCEA & $3.32 \pm 0.68$ & $3.08 \pm 0.66$ & $3.97 \pm 1.04^{+}$ & $3.88 \pm 1.16^{+}$ & $4.47 \pm 1.21^{+}$ & $5.33 \pm 1.56^{+}$ & $4.87 \pm 1.22^{+}$ & $4.28 \pm 1.07^{+}$ & $4.30 \pm 1.14^{+}$ \\
\hline & Control & $2709 \pm 500$ & $2484 \pm 773$ & $2256 \pm 725$ & $2228 \pm 568^{+}$ & $2150 \pm 637$ & $1967 \pm 763^{+}$ & $1647 \pm 648^{+}$ & $1731 \pm 378^{+}$ & $1790 \pm 428^{+}$ \\
\hline \multirow[t]{3}{*}{ SVRI, dyne'sec' $\mathrm{cm}^{-5^{\prime}} \mathrm{m}^{-2}$} & El & $2458 \pm 707$ & $2120 \pm 600$ & $1933 \pm 287^{+}$ & $1953 \pm 290$ & $1993 \pm 482$ & $2035 \pm 491^{+}$ & $1677 \pm 456^{+}$ & $1846 \pm 277^{+}$ & $1788 \pm 329^{+}$ \\
\hline & PCEA & $2912 \pm 970$ & $2299 \pm 791$ & $2059 \pm 892$ & $2112 \pm 733^{+}$ & $2223 \pm 554$ & $2086 \pm 405$ & $2123 \pm 487^{+}$ & $2205 \pm 623^{*+}$ & $2078 \pm 604^{+}$ \\
\hline & Control & $11.3 \pm 3.6$ & $14.0 \pm 4.0^{\#+}$ & $11.8 \pm 3.7^{\#}$ & $12.7 \pm 3.5^{\#+}$ & $7.6 \pm 3.7^{+}$ & $5.9 \pm 3.1^{+}$ & $5.0 \pm 4.0^{+}$ & $4.6 \pm 4.2^{+}$ & $5.8 \pm 4.6^{+}$ \\
\hline \multirow[t]{3}{*}{ CVP, mm Hg } & El & $12.5 \pm 3.1$ & $16.8 \pm 3.2^{+}$ & $14.4 \pm 2.5^{+}$ & $14.9 \pm 2.3^{+}$ & $8.9 \pm 3.3^{+}$ & $7.2 \pm 4.8^{+}$ & $6.3 \pm 4.2^{+}$ & $5.4 \pm 5.3^{+}$ & $4.9 \pm 3.3^{+}$ \\
\hline & PCEA & $11.4 \pm 2.67$ & $15.0 \pm 3.8^{+}$ & $13.0 \pm 3.0^{+}$ & $13.4 \pm 2.8^{+}$ & $8.3 \pm 4.3^{+}$ & $4.3 \pm 3.5^{\#+}$ & $4.1 \pm 3.3^{+}$ & $4.6 \pm 4.0^{+}$ & $5.4 \pm 3.8^{+}$ \\
\hline & Control & $689 \pm 243$ & $797 \pm 227$ & $765 \pm 168$ & $711 \pm 117$ & $729 \pm 169$ & $724 \pm 165$ & $695 \pm 188$ & $715 \pm 199$ & $710 \pm 145$ \\
\hline \multirow[t]{3}{*}{ GEDVI, $\mathrm{ml} / \mathrm{m}^{2}$} & El & $674 \pm 215$ & $661 \pm 250$ & $696 \pm 153$ & $704 \pm 251$ & $680 \pm 149$ & $659 \pm 106$ & $660 \pm 125$ & $661 \pm 107$ & $682 \pm 115$ \\
\hline & PCEA & $653 \pm 143$ & $646 \pm 159$ & $722 \pm 116$ & $665 \pm 146$ & $683 \pm 251$ & $728 \pm 139$ & $728 \pm 133$ & $720 \pm 125$ & $799 \pm 148$ \\
\hline & Control & $697 \pm 116$ & $537 \pm 169$ & $567 \pm 142$ & $565 \pm 145$ & $803 \pm 412$ & $773 \pm 307$ & $770 \pm 255$ & $744 \pm 412$ & $915 \pm 339$ \\
\hline \multirow[t]{3}{*}{$\mathrm{dPmax}, \mathrm{mm} \mathrm{Hg} / \mathrm{sec}$} & El & $542 \pm 136$ & $479 \pm 150$ & $552 \pm 141$ & $567 \pm 201$ & $803 \pm 412^{+}$ & $849 \pm 288^{+}$ & $880 \pm 293^{+}$ & $1015 \pm 421^{+}$ & $997 \pm 353^{+}$ \\
\hline & PCEA & $561 \pm 203$ & $457 \pm 159$ & $536 \pm 179$ & $578 \pm 219$ & $843 \pm 263^{+}$ & $813 \pm 177^{+}$ & $909 \pm 284^{+}$ & $877 \pm 243^{+}$ & $857 \pm 195^{+}$ \\
\hline & Control & $24.6 \pm 6.1$ & $21.0 \pm 6.6^{+}$ & $22.2 \pm 7.0$ & $22.0 \pm 5.6^{+}$ & $22.3 \pm 5.8$ & $22.3 \pm 4.7$ & $24.0 \pm 6.3$ & $22.0 \pm 5.4$ & $21.7 \pm 5.3$ \\
\hline \multirow[t]{3}{*}{ GEF, \% } & $\mathrm{El}$ & $26.2 \pm 7.30$ & $23.5 \pm 5.4$ & $26.1 \pm 6.3$ & $26.0 \pm 7.0$ & $26.7 \pm 7.7$ & $22.6 \pm 5.0$ & $24.2 \pm 6.1$ & $24.0 \pm 5.7$ & $22.9 \pm 5.5$ \\
\hline & PCEA & $21.8 \pm 7.2$ & $21.2 \pm 6.1$ & $24.6 \pm 6.2^{+}$ & $23.8 \pm 6.5$ & $23.9 \pm 5.1$ & $22.8 \pm 5.7$ & $21.6 \pm 6.3$ & $19.0 \pm 5.1$ & $19.6 \pm 4.8$ \\
\hline & Control & $9.0(7.0-10.0)$ & $11.0(8.0-14.0)^{+}$ & $9.0(8.0-11.0)$ & $10.0(7.0-11.0)$ & $8.0(5.0-12.0)$ & $8.0(6.0-11.0)$ & $10.0(6.0-11.0)$ & $8.0(5.0-14.0)$ & $9.0(8.0-13.0)$ \\
\hline \multirow[t]{2}{*}{ EVLWI, ml/kg } & $\mathrm{El}$ & $9.0(7.0-9.5)$ & $8.5(6.8-10.5)$ & $9.0(7.0-10.3)$ & $8.0(6.8-10.0)$ & $7.5(6.0-11.8)$ & $6.5(6.0-10.3)$ & $6.0(5.8-7.3)^{+}$ & $7.00(6.8-8.8)$ & $7.5(6.0-9.3)$ \\
\hline & PCEA & $8.0(6.3-9.8)$ & $9.5(7.0-11.0)$ & $8.0(7.3-11.8)$ & $8.0(7.0-10.5)$ & $8.0(7.0-12.8)$ & $6.5(6.0-8.0)$ & $7.0(5.3-8.8)$ & $7.5(6.0-9.8)$ & $7.5(7.0-10.8)$ \\
\hline
\end{tabular}

Data are presented as mean \pm SD or median $\left(25^{\text {th }}-75^{\text {th }}\right.$ percentiles).

* $P<0.05$ compared with the control group

$\# P<0.05$ compared with the El group:

$+P<0.05$ compared with baseline (after induction of anesthesia).

Control, control group; El, epidural infusion group; PCEA, patient controlled epidural analgesia group; MAP, mean arterial pressure; HR, heart rate; Cl, cardiac index; CFI, cardiac function index; SVRI, systemic vascular resistance index; CVP, central venous pressure; GEDVI, global end-diastolic volume index; dPmax, left ventricle contractility index; GEF, global ejection fraction; EVLWI, extravascular lung water index. 
Table 3 Laboratory parameters in patients undergoing OPCAB

\begin{tabular}{|c|c|c|c|c|c|c|c|c|}
\hline \multirow[t]{2}{*}{ Characteristic } & \multirow[t]{2}{*}{ Group } & \multicolumn{7}{|c|}{ Period } \\
\hline & & After induction of anesthesia & $\begin{array}{l}\text { End of } \\
\text { Operation }\end{array}$ & 2 hours & 6 hours & 12 hours & 18 hours & 24 hours \\
\hline & Control & $7.39 \pm 0.04$ & $7.34 \pm 0.05^{+}$ & $7.30 \pm 0.04^{+}$ & $7.33 \pm 0.03^{+}$ & $7.36 \pm 0.03^{+}$ & $7.39 \pm 0.03$ & $7.40 \pm 0.06$ \\
\hline \multirow[t]{3}{*}{$\mathrm{pH}$} & El & $7.37 \pm 0.03$ & $7.34 \pm 0.04^{+}$ & $7.30 \pm 0.06^{+}$ & $7.34 \pm 0.04^{+}$ & $7.38 \pm 0.03^{+}$ & $7.39 \pm 0.03^{+}$ & $7.41 \pm 0.03^{+}$ \\
\hline & PCEA & $7.38 \pm 0.03$ & $7.34 \pm 0.05^{+}$ & $7.30 \pm 0.04^{+}$ & $7.35 \pm 0.04^{+}$ & $7.37 \pm 0.04$ & $7.40 \pm 0.03$ & $7.40 \pm 0.03^{+}$ \\
\hline & Control & $38.2 \pm 3.49$ & $39.0 \pm 5.56$ & $41.1 \pm 5.05$ & $39.0 \pm 4.21$ & $38.0 \pm 5.10$ & $36.8 \pm 4.14$ & $33.7 \pm 4.13^{+}$ \\
\hline \multirow[t]{3}{*}{$\mathrm{PaCO}_{2}, \mathrm{~mm} \mathrm{Hg}$} & El & $40.1 \pm 4.41$ & $39.4 \pm 5.16$ & $42.1 \pm 6.90$ & $38.5 \pm 4.93$ & $35.7 \pm 4.82^{+}$ & $36.1 \pm 3.61^{+}$ & $34.2 \pm 2.86^{+}$ \\
\hline & PCEA & $39.2 \pm 3.77$ & $39.2 \pm 5.36$ & $42.1 \pm 4.34$ & $37.8 \pm 3.29$ & $36.7 \pm 3.97$ & $34.5 \pm 3.73^{+}$ & $33.9 \pm 4.38^{+}$ \\
\hline & Control & $287 \pm 100$ & $243 \pm 108$ & $275 \pm 73$ & $282 \pm 80$ & $273 \pm 76$ & $272 \pm 139$ & $302 \pm 98$ \\
\hline \multirow[t]{3}{*}{$\mathrm{PaO}_{2} / \mathrm{FiO}_{2}, \mathrm{~mm} \mathrm{Hg}$} & El & $323 \pm 110$ & $272 \pm 93$ & $292 \pm 97$ & $296 \pm 71$ & $290 \pm 87$ & $281 \pm 89$ & $282 \pm 110$ \\
\hline & PCEA & $336 \pm 104$ & $257 \pm 83$ & $300 \pm 71$ & $303 \pm 103$ & $298 \pm 91$ & $340 \pm 129^{*}$ & $347 \pm 124$ \\
\hline & Control & $1.00 \pm 0.28$ & $1.28 \pm 0.63$ & $1.50 \pm 0.74^{+}$ & $1.75 \pm 0.76^{+}$ & $1.74 \pm 0.87^{+}$ & $1.80 \pm 0.58^{+}$ & $1.50 \pm 0.40^{+}$ \\
\hline \multirow[t]{3}{*}{ Lactate, mmol/l } & $\mathrm{El}$ & $1.07 \pm 0.78$ & $1.16 \pm 0.36$ & $1.38 \pm 0.62$ & $1.50 \pm 0.74^{+}$ & $1.46 \pm 0.81$ & $1.44 \pm 0.44$ & $1.20 \pm 0.37$ \\
\hline & PCEA & $1.06 \pm 0.36$ & $1.09 \pm 0.42$ & $1.40 \pm 0.80^{+}$ & $1.81 \pm 0.86^{+}$ & $1.70 \pm 0.77^{+}$ & $1.35 \pm 0.44^{+*}$ & $1.48 \pm 0.71^{+}$ \\
\hline & Control & $5.71 \pm 1.51$ & $6.77 \pm 2.00^{+}$ & $8.01 \pm 2.67^{+}$ & $8.42 \pm 3.15^{+}$ & $7.22 \pm 2.56^{+}$ & $6.17 \pm 1.47$ & $6.33 \pm 1.36$ \\
\hline \multirow[t]{3}{*}{ Glucose, mmol/l } & El & $5.16 \pm 1.40$ & $5.97 \pm 1.44$ & $7.28 \pm 2.24^{+}$ & $6.90 \pm 1.84^{+}$ & $6.25 \pm 1.96^{+}$ & $5.64 \pm 1.32$ & $6.81 \pm 2.34^{+}$ \\
\hline & PCEA & $5.60 \pm 1.48$ & $6.41 \pm 2.18^{+}$ & $7.68 \pm 2.79^{+}$ & $7.84 \pm 2.64^{+}$ & $7.12 \pm 1.92^{+}$ & $6.13 \pm 1.68^{+}$ & $6.59 \pm 1.52$ \\
\hline & Control & $219 \pm 80$ & - & - & $984 \pm 334^{+}$ & - & $714 \pm 297^{+}$ & - \\
\hline \multirow[t]{3}{*}{ Cortisol, nmol/l } & El & $296 \pm 111$ & - & - & $861 \pm 366^{+}$ & - & $618 \pm 322^{+}$ & - \\
\hline & PCEA & $303 \pm 108$ & - & - & $832 \pm 371^{+}$ & - & $591 \pm 223^{+}$ & - \\
\hline & Control & $0.01 \pm 0.00$ & - & - & $0.32 \pm 0.30^{+}$ & - & $0.25 \pm 0.35$ & - \\
\hline \multirow[t]{2}{*}{ Troponin T, ng/ml } & El & $0.01 \pm 0.00$ & - & - & $0.20 \pm 0.11^{+}$ & - & $0.10 \pm 0.08$ & - \\
\hline & PCEA & $0.01 \pm 0.00$ & - & - & $0.26 \pm 0.20^{+}$ & - & $0.33 \pm 0.52$ & - \\
\hline
\end{tabular}

Data are presented as mean \pm SD.

${ }^{*} P<0.05$ compared with the control group;

${ }^{+} P<0.05$ compared with baseline (after induction of anesthesia).

Control, control group; El, epidural infusion group; PCEA, patient controlled epidural analgesia group.

and adverse events (not shown). There were no complications related to EA.

\section{Discussion}

The present study demonstrates that EA with ropivacaine/fentanyl causes a moderate decrease in arterial pressure and prevents reduction of GEF and lung fluid accumulation during OPCAB. The epidural administration of ropivacaine and fentanyl reduces the requirement of nitroglycerin and intravenous agents for anesthesia and analgesia, but requires more frequent perioperative therapy with colloids and inotropes/ vasopressors. Postoperatively, EI provides adequate analgesia and improves left ventricle myocardial contractility. Moreover, EI combined with PCA is associated with mild hyperventilation, transient improvement of oxygenation and tissue perfusion and decreased duration of mechanical ventilation after OPCAB in comparison with the control group.

The postoperative improvement of lung function observed in the PCEA group was accompanied by reduced time to tracheal extubation, but the durations of ICU and hospital stays did not differ significantly. These results are in accordance with other studies of EA

Table 4 Postoperative pain as assessed by visual analog scale (VAS) in patients undergoing OPCAB

\begin{tabular}{llllll}
\hline Characteristic & Group & \multicolumn{3}{c}{ Time after surgery } \\
& & $\mathbf{6}$ hours & $\mathbf{1 2}$ hours & $\mathbf{1 8}$ hours & $\mathbf{2 4}$ hours \\
\hline \multirow{3}{*}{ VAS at rest } & Control & $20(0-30)$ & $20(0-35)$ & $20(0-30)$ & $10(0-20)$ \\
& El & $15(0-30)$ & $10(0-20)$ & $10(0-20)$ & $0(0-20)$ \\
& PCEA & $0(0-20)$ & $0(0-10)^{*}$ & $0(0-18)$ & $0(0-18)$ \\
VAS during coughing & Control & $30(0-55)$ & $30(20-50)$ & $30(20-50)$ & $30(20-50)$ \\
& El & $20(0-40)$ & $30(20-40)$ & $30(10-50)$ & $30(20-40)$ \\
\hline
\end{tabular}

Data are presented as median $\left(25^{\text {th }}-75^{\text {th }}\right.$ percentiles). ${ }^{*} P<0.05$ compared with the control group.

Control, control group; El, epidural infusion group; PCEA, patient controlled epidural analgesia group. 
Table 5 Requirements of drugs and volume balance in patients undergoing OPCAB

\begin{tabular}{|c|c|c|c|}
\hline \multirow[t]{2}{*}{ Characteristic } & \multicolumn{3}{|c|}{ Groups } \\
\hline & Control $(n=30)$ & EI $(n=30)$ & PCEA $(n=30)$ \\
\hline Propofol during surgery, mg & $1200(988-1400)$ & $1000(775-1100)^{*}$ & $1100(900-1200)$ \\
\hline Fentanyl during surgery, mg & $1.2(1.1-1.3)$ & $0.6(0.5-0.7)^{*}$ & $0.6(0.5-0.9)^{*}$ \\
\hline Fentanyl during first 24 hrs after surgery, mg & $0.70(0.50-1.00)$ & $0.27(0.20-0.30)$ & $0.30(0.20-0.35)$ \\
\hline Ropivacaine during surgery, mg & - & $75(75-100)$ & $75(75-100)$ \\
\hline Ropivacaine during first 24 hrs after surgery, mg & - & $250(192-300)$ & $300(200-348)^{\#}$ \\
\hline Nitroglycerin during surgery, mg & $11.0(6.7-19.5)$ & $1.0(0.0-2.3)^{*}$ & $2.2(0.0-4.0)^{*}$ \\
\hline Nitroglycerin during first 24 hrs after surgery, mg & $24.0(16.0-33.5)$ & $10.0(0.0-15.0)^{*}$ & $9.0(0.0-18.5)^{*}$ \\
\hline Inotropes/vasopressors during surgery, number of patients & 5 & $15^{*}$ & 11 \\
\hline Inotropes/vasopressors during first 24 hrs after surgery, number of patients & 0 & 5 & 1 \\
\hline Colloids during surgery, number of patients & 11 & $21^{*}$ & $24^{*}$ \\
\hline Colloids during first 24 hrs after surgery, number of patients & 7 & $16^{*}$ & $6^{\#}$ \\
\hline Fluid balance during surgery, $\mathrm{ml}$ & $1614 \pm 537$ & $1949 \pm 475^{*}$ & $1919 \pm 354$ \\
\hline
\end{tabular}

Data are presented as mean $\pm S D$, median $\left(25^{\text {th }}-75^{\text {th }}\right.$ percentiles), or number of patients.

* $P<0.05$ compared with the control group;

\# $P<0.05$ compared with the El group.

Control: control group; El, epidural infusion group; PCEA, patient controlled epidural analgesia group.

in coronary surgery and can be explained by a wide range of confounding factors that are able to influence the length of hospitalization [8,10-17]. However, according to Sharma et al., the use of epidural analgesia in obese patients can shorten the ICU stay after OPCAB [13]. This effect was explained by a reduced incidence of respiratory complications in this category of high-risk patients. Earlier hospital discharge after EA for CABG was also reported by de Vries et al. [18].

After induction of anesthesia, all the groups presented with myocardial dysfunction and systemic vasoconstriction, as judged by the occurrence of bradycardia, decreased CI, CFI and dPmax, and increased SVRI. The restraint of the heart was accompanied by a rise in CVP, paralleled by a decline in GEF and an increase in EVLW in the control group. This is typical for OPCAB and can be explained by "enucleation" of the heart, kinking of vessels, reduction of venous return, and impairment of ventricular geometry $[1,19]$. After OPCAB, we observed a reduction of systemic vascular tone and a rise in myocardial performance. These changes are consistent with other investigations of CABG and may result from the restoration of coronary blood flow and reversal of myocardial depression by goal-directed hemodynamic optimization $[1,19,20]$. As shown in several previous studies, volumetric parameters measured by transpulmonary thermodilution, such as GEDVI, which we used for hemodynamic optimization, is a more sensitive indicator of preload compared to CVP and can serve as guidance for colloid administration [19-24]. Most likely, this allowed us to maintain normal preload in all groups.

During OPCAB, EA decreased MAP transiently and partly prevented the decline in GEF as well as lung water accumulation, which we observed in the control group. In addition, in contrast to the control group, postoperative EI prompted a significant increase in dPmax. Although displaying only statistical intragroup differences, these changes can be explained by the hemodynamic effects of epidural blockade, including afterload reduction, that can lead to improvements in myocardial performance and pulmonary blood flow $[7,10,25,26]$. Recently, similar findings were noticed by investigators, who used EA in on-pump CABG $[25,26]$.

The changes in hemodynamics observed during and after OPCAB were accompanied by transient metabolic acidosis and increased plasma lactate in parallel with hyperglycemia and rise in cortisol and troponin- $\mathrm{T}$ plasma concentrations in all groups. These data are consistent with results published by other authors and can be explained by tissue hypoperfusion, inflammation, surgical stress and myocardial damage caused by CABG $[1,14,26,27]$.

We found that epidural analgesia after OPCAB resulted in mild hyperventilation. Moreover, the PCEA with ropivacaine/fentanyl led to transient postoperative improvement in arterial oxygenation and decreased lactate, possibly due to improvement of pulmonary and systemic perfusion [28]. In addition to these mechanisms, the advantageous respiratory effects of epidural blockade in cardiac surgery were associated with reduced incidence of postoperative atelectases and improved quality of analgesia [15-17,28]. In our study, epidural anesthesia and analgesia provided adequate pain control, similar to that observed after administration of opioids in the control group, as confirmed by VAS score $<30 \mathrm{~mm}$ in both epidural groups; optimal analgesia was observed after PCEA. Thus, the combined effects of analgesia, pulmonary vasodilation, prevention 
of lung edema and improvement of pulmonary mechanics might have resulted in a better lung function in the PCEA group that allowed earlier termination of respiratory support.

In the present study, the analgesic effect of epidural administration of ropivacaine and fentanyl reduced the requirements of intravenously administered fentanyl and propofol for general anesthesia. The postoperative use of PCEA led to increased consumption of ropivacaine but did not influence the incidence of adverse events after $\mathrm{OPCAB}$, like oversedation, pruritus, nausea, vomiting or arrhythmias. This is consistent with other investigations in this field. By contrast, several authors report reduced incidence of atrial fibrillation after EA for coronary surgery, probably due to the sympatholythic action of epidural blockade [11,15,28-30]. Thus, by reducing the requirements in opioids, time to tracheal extubation and number of complications, EA can become part of a fast-track concept of cardiac anesthesia that is aimed to achieve cost-savings, and improve clinical outcome, as suggested by recent workers [31]. Despite several beneficial effects of EA, we found increased requirements for colloids and inotrope/vasopressor support to maintain targeted hemodynamic values. This led to increased intraoperative fluid balance that also might have influenced cardiopulmonary function. In parallel, thoracic epidural administration of ropivacaine and fentanyl resulted in significant reduction of perioperative nitroglycerin requirement. These changes can be explained by vasodilation and redistribution of blood volume caused by EA and analgesia. Thus the hypotensive effect of epidural blockade should not be underestimated, especially in hemodynamically unstable patients. Similar results were obtained by other authors studying EA in coronary surgery $[10,11,28]$.

A limitation of this patient-controlled mode of analgesia is that its use depends on the condition of the patient. Moreover, some of the effects of PCEA on cardiopulmonary function occurred transiently and their clinical significances should be interpreted with caution. Therefore, larger studies are warranted to confirm our findings and to determine the optimal regimens of EA and postoperative analgesia in $\mathrm{OPCAB}$ patients.

\section{Conclusion}

The use of EA during OPCAB reduces transiently arterial pressure and prevents lung fluid accumulation. Being a component of a goal-directed perioperative strategy, the epidural administration of ropivacaine/fentanyl can improve myocardial performance and provide analgesia comparable with intravenous opioids, although increasing the requirements for fluids and vasoactive therapies. After OPCAB, continuous EI combined with PCEA increases tissue perfusion and improves lung function, thus shortening the duration of mechanical ventilation.

\section{List of abbreviations}

CABG: coronary artery bypass grafting; $\mathbf{C l}$ : cardiac index; $\mathbf{C F I}$-cardiac function index; CO: cardiac output; CPB: cardiopulmonary bypass; CVP: central venous pressure; $\mathbf{d P m a x}$ : left ventricle contractility index; EA: epidural anesthesia; El: epidural infusion; ECG: electrocardiogram; EVLWI: extravascular lung water index; $\mathbf{F i O}_{2}$ : fraction of inspired oxygen; GEDVI: global end-diastolic volume index; GEF: global ejection fraction; $\mathbf{H b}$ : blood hemoglobin concentration; HR: heart rate; ICU: intensive care unit; IV: intravenously; MAP: mean arterial pressure; OPCAB: off-pump coronary artery bypass grafting; $\mathrm{PaCO}_{2}$ : partial pressure of carbon dioxide in arterial blood; $\mathbf{P a O}_{2}$ : partial pressure of oxygen in arterial blood; PCEA: patientcontrolled epidural analgesia; $\mathbf{S p O}_{2}$ : peripheral oxygen saturation; SVRI: systemic vascular resistance index; VAS: visual analog scale.

\section{Acknowledgements and Funding}

The study was presented, in part, at the $21^{\text {st }}$ Annual Congress of the European Society of Intensive Care Medicine, Lisbon, Portugal, September 22, 2008, and supported by a grant from the Government of Arkhangelsk region "Young Pomor scientists" and by departmental funds. The authors thank Dr. Denis Uvarov, Dr. Vsevolod Kuzkov, Dr. Andrey Charigin and Dr. Marat Zinurov for their assistance in organizing the study, and the personnel of the operation theatre and the cardiosurgical ICU, City Hospital \#1 of Arkhangelsk, for their kind help during the conduct of the investigation.

\section{Author details}

${ }^{1}$ Department of Anesthesiology and Intensive Care Medicine, Northern State Medical University, Troitsky avenue 51, Arkhangelsk, 163000, Russian Federation. ${ }^{2}$ Department of Anesthesiology and Intensive Care Medicine, City Hospital \#1, Suvorov Street 1, Arkhangelsk, 163001, Russian Federation. ${ }^{3}$ Department of Clinical Medicine (Anesthesiology), Faculty of Medicine, University of Tromsø, MH-Breivika, Tromsø, 9038, Norway. ${ }^{4}$ Department of Anesthesiology, University Hospital of North Norway, Sykehusveien 38, Tromsø, 9038, Norway.

\section{Authors' contributions}

MYK, AVE and AAS participated in the design of the study, collected and analyzed the data, prepared figures and tables and drafted the manuscript. LJB participated in the design of the study and drafted the manuscript. All authors have read and approved the final manuscript.

\section{Competing interests}

The authors declare that they have no competing interests.

Received: 5 April 2011 Accepted: 18 September 2011 Published: 18 September 2011

\section{References}

1. Chassot PG, van der Linden P, Zaugg M, Mueller XM, Spahn DR: Off-pump coronary artery bypass surgery: physiology and anaesthetic management. Br J Anaesth 2004, 92:400-413.

2. Ngaage DL: Off-pump coronary artery bypass grafting: simple concept but potentially sublime scientific value. Med Sci Monit 2004, 10:RA47-54.

3. Cheng DCH, Bainbridge D: Fast-track cardiac anesthesia management in on-pump and off-pump coronary artery bypass surgery. In Perioperative Care in Cardiac Anesthesia and Surgery. Edited by: Cheng DCH, David TE. Philadelphia: Lippincott Williams and Wilkins; 2006:59-108.

4. Scott BH, Seifert FC, Grimson R, Glass PS: Resource utilization in on- and off-pump coronary artery surgery: factors influencing postoperative length of stay: an experience of 1,746 consecutive patients undergoing fast-track cardiac anesthesia. J Cardiothorac Vasc Anesth 2005, 19:26-31.

5. Boldt J: Clinical review: Hemodynamic monitoring in the intensive care unit. Crit Care 2002, 6:52-59.

6. Ngaage DL: Off-pump coronary artery bypass grafting: the myth, the logic and the science. Eur J Cardiothor Surg 2003, 24:557-570. 
7. Kessler P, Neidhart G, Lischke V, Bremerich DH, Aybek T, Dogan S, et al: Coronary bypass operation with complete median sternotomy in awake patients with high thoracic peridural anesthesia. Anaesthesist 2002, 51:533-538.

8. Nesković V, Milojević P: High thoracic epidural anesthesia in coronary surgery. Med Pregl 2003, 56:152-156.

9. The Task Force for Preoperative Cardiac Risk Assessment and Perioperative Cardiac Management in Non-cardiac Surgery of the European Society of Cardiology (ESC) and endorsed by the European Society of Anaesthesiology (ESA): Guidelines for pre-operative cardiac risk assessment and perioperative cardiac management in non-cardiac surgery. Eur $J$ Anaesthesiol 2010, 27:92-137.

10. Casalino S, Mangia F, Stelian E, Novelli E, Diena M, Tesler U: High thoracic epidural anesthesia in cardiac surgery. Risk factors for arterial hypotension. Tex Heart Inst J 2006, 33:148-153.

11. Salvi L, Parolari A, Veglia F, Brambillasca C, Gregu S, Sisillo E: High thoracic epidural anesthesia in coronary artery bypass surgery: a propensitymatched study. J Cardiothorac Vasc Anesth 2007, 21:810-815.

12. Scott NB, Turfrey DJ, Ray DA, Nzewi O, Sutcliffe NP, Lal AB, et al: A prospective randomized study of the potential benefits of thoracic epidural anesthesia and analgesia in patients undergoing coronary artery bypass grafting. Anesth Analg 2001, 93:528-535.

13. Sharma M, Mehta $Y$, Sawhney $R$, Vats $M$, Trehan $N$ : Thoracic epidural analgesia in obese patients with body mass index of more than $30 \mathrm{~kg} /$ $\mathrm{m} 2$ for off pump coronary artery bypass surgery. Ann Card Anaesth 2010, 13:28-33.

14. Barrington MJ, Kluger R, Watson R, Scott DA, Harris KJ: Epidural anesthesia for coronary artery bypass surgery compared with general anesthesia alone does not reduce biochemical markers of myocardial damage. Anesth Analg 2005, 100:921-928.

15. Priestley MC, Cope L, Halliwell R, Gibson P, Chard RB, Skinner M, et al: Thoracic epidural anesthesia for cardiac surgery: the effects on tracheal intubation time and length of hospital stay. Anesth Analg 2002, 94:275-282.

16. Stenseth R, Bjella L, Berg EM, Christensen O, Levang OW, Gisvold SE: Effects of thoracic epidural analgesia on pulmonary function after coronary artery bypass surgery. Eur J Cardiothorac Surg 1996, 10:859-865.

17. Hansdottir V, Philip J, Olsen MF, Eduard C, Houltz E, Ricksten SE: Thoracic epidural versus intravenous patient-controlled analgesia after cardiac surgery: a randomized controlled trial on length of hospital stay and patient-perceived quality of recovery. Anesthesiology 2006, 104:142-151.

18. de Vries AJ, Mariani MA, van der Maaten JM, Loef BG, Lip H: To ventilate or not after minimally invasive direct coronary artery bypass surgery: the role of epidural anesthesia. J Cardiothorac Vasc Anesth 2002, 16:21-26.

19. Goepfert MS, Reuter DA, Akyol D, Lamm P, Kilger E, Goetz A: Goal-directed fluid management reduces vasopressor and catecholamine use in cardiac surgery patients. Intensive Care Med 2007, 33:96-103.

20. Kirov MY, Lenkin Al, Kuzkov W, Suborov EV, Slastilin W, Borodin W, et al: Single transpulmonary thermodilution in off-pump coronary artery bypass grafting: haemodynamic changes and effects of different anaesthetic techniques. Acta Anaesthesiol Scand 2007, 51:426-433.

21. Kumar A, Anel R, Bunnell E, Habet K, Zanotti S, Marshall S, et al: Pulmonary artery occlusion pressure and central venous pressure fail to predict ventricular filling volume, cardiac performance, or the response to volume infusion in normal subjects. Crit Care Med 2004, 32:691-699.

22. Hofer CK, Furrer L, Matter-Ensner S, Maloigne M, Klaghofer R, Genoni M, et al: Volumetric preload measurement by thermodilution: a comparison with transoesophageal echocardiography. Br J Anaesth 2005, 94:748-755.

23. Pölönen $P$, Ruokonen $E$, Hippeläinen $M$, Pöyhönen $M$, Takala J: A prospective, randomized study of goal-oriented hemodynamic therapy in cardiac surgical patients. Anesth Analg 2000, 90:1052-1059.

24. Smetkin AA, Kirov MY, Kuzkov W, Lenkin Al, Eremeev AV, Slastilin WY, et al: Single transpulmonary thermodilution and continuous monitoring of central venous oxygen saturation during off-pump coronary surgery. Acta Anaesth Scand 2009, 53:505-514.

25. Lenkutis $T$, Benetis R, Sirvinskas E, Raliene L, Judickaite L: Effects of epidural anesthesia on intrathoracic blood volume and extravascular lung water during on-pump cardiac surgery. Perfusion 2009, 24:243-248.

26. Kiliçkan L, Solak M, Bayindir O: Thoracic epidural anesthesia preserves myocardial function during intraoperative and postoperative period in coronary artery bypass grafting operation. J Cardiovasc Surg 2005, 46:559-567.

27. Caputo M, Alwair H, Rogers CA, Ginty M, Monk C, Tomkins S, et al: Myocardial, inflammatory, and stress responses in off-pump coronary artery bypass graft surgery with thoracic epidural anesthesia. Ann Thorac Surg 2009, 87:1119-1126.

28. Tenenbein PK, Debrouwer R, Maguire D, Duke PC, Muirhead B, Enns J, et al: Thoracic epidural analgesia improves pulmonary function in patients undergoing cardiac surgery. Can J Anaesth 2008, 55:344-350.

29. Curatolo M: Adding regional analgesia to general anaesthesia: increase of risk or improved outcome? Eur J Anaesth 2010, 27:586-591.

30. Bakhtiary F, Therapidis P, Dzemali O, Ak K, Ackermann H, Meininger D, et al: Impact of high thoracic epidural anesthesia on incidence of perioperative atrial fibrillation in off-pump coronary bypass grafting: a prospective randomized study. J Thorac Cardiovasc Surg 2007, 134:460-464.

31. Myles PS, Mcllroy D: Fast-track cardiac anesthesia: choice of anesthetic agents and techniques. Semin Cardiothorac Vasc Anesth 2005, 9:5-16.

\section{Pre-publication history}

The pre-publication history for this paper can be accessed here: http://www.biomedcentral.com/1471-2253/11/17/prepub

doi:10.1186/1471-2253-11-17

Cite this article as: Kirov et al:: Epidural anesthesia and postoperative analgesia with ropivacaine and fentanyl in off-pump coronary artery bypass grafting: a randomized, controlled study. BMC Anesthesiology 2011 11:17.

\section{Submit your next manuscript to BioMed Central and take full advantage of:}

- Convenient online submission

- Thorough peer review

- No space constraints or color figure charges

- Immediate publication on acceptance

- Inclusion in PubMed, CAS, Scopus and Google Scholar

- Research which is freely available for redistribution

Submit your manuscript at www.biomedcentral.com/submit
Biomed Central 